Archived version from NCDOCKS Institutional Repository http://libres.uncg.edu/ir/asu/

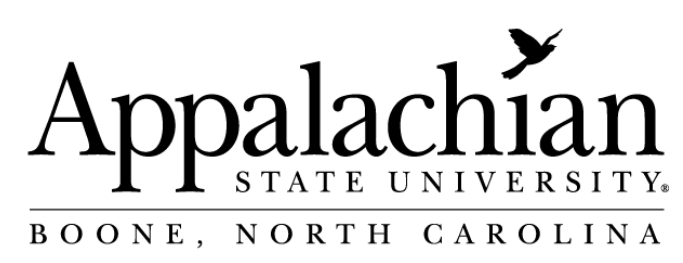

\title{
The Evidence Supports Douglas Merritte as Little Albert
}

\author{
Authors: Hall P. Beck, Sharman Levinson and Gary Irons
}

\section{No Abstract}

Hall P. Beck, Sharman Levinson and Gary Irons(2010) The Evidence Supports Douglas Merritte as Little Albert American Psychologist, 65, 301-303. (doi: 10.1037/a0019444) 
the longest of the six 1920 issues; it was about $11 \%$ ( 9 pp.) longer than the mean of 79 pages per issue, suggesting that publication would not have been delayed for want of manuscripts.

(e) A final consideration is that no one has cited any 1920 comment that publica tion of the February issue was delayed. The absence of contemporaneous comments implies that at worst, the actual publication was not remarkably delayed.

\section{REFERENCES}

Beck, H. P., Levinson, S., \& Irons, G. (2009). Finding Little Albert: A journey to John B. Watson's infant laboratory. American Psychologist, 64, 605-614. doi:10.1037/a0017234

Beck, L. F. (1937). Watson, J. B. Experimental investigation of babies. Psychological $A b$ stracts, 11, 684. (Abstract No. 6061)

Beck, L. F. (1938). A review of sixteen-millimeter films in psychology and allied sciences. Psychological Bulletin, 35, 127-169. doi: 10.1037/h0054375

C. H. Stoelting Co. (1937). Psychological and physiological apparatus and supplies: Supplement. Chicago, IL: Author.

Cohen, D. (1979). J. B. Watson: The founder of behaviorism. A biography. London, England: Routledge \& Kegan Paul.

Griffith, C. R. (1920a). The decrease of afternystagmus during repeated rotation. The $L a-$ ryngoscope, 30, 129-137.

Griffith, C. R. (1920b). The organic effects of repeated bodily rotation. Journal of Experimental Psychology, 3, 15-47. doi:10.1037/ h0069767

Watson, J. B. (1930). Behaviorism (rev. ed.). New York, NY: Norton.

Watson, J. B., \& Rayner, R. (1920). Conditioned emotional reactions. Journal of Experimental Psychology, 3, 1-14. doi:10.1037/h0069608

\section{The Evidence Supports Douglas Merritte as Little Albert}

\author{
Hall P. Beck \\ Appalachian State University \\ Sharman Levinson \\ The American University of Paris
}

Gary Irons

Finksburg, MD summarized the results of a seven-year search to determine the identity and fate of "Little Albert." Examinations of Watson's scientific production, correspondence, and public documents suggested that an employee at the Harriet Lane Hospital was Albert's mother. The child's birth records and contact with the woman's descendents led us to Douglas Merritte, the individual we believe to be Watson and Rayner's (1920) famous participant. Powell (2010, this issue) and Reese (2010, this issue) brought forth considerations that they believe are contrary to our conclusion. We thank these authors for their interest in our work and the American Psychologist for allowing us to elaborate on and provide additional support for the thesis that Doug las was Little Albert.

\section{Albert's First Year}

Powell (2010) contended that Douglas could not be Albert because "the real Al bert was not born in the hospital but was brought to the hospital" (p. 299). Watson and Rayner (1920) are quoted to support this position:

This infant was reared almost from birth in a hospital environment; his mother was a wet nurse in the Harriet Lane Home for Invalid Chil dren. Albert's life was normal: he was healthy from birth and one of the best developed youngsters ever brought to the hospital, weighing twenty-one pounds at nine months of age. (p. 1)

This well-known passage is consistent with what we know of Douglas's first year. The hospital that Albert was brought to was the Harriet Lane Home. This was the same hospital that Douglas was brought to after his mother began working there. Perhaps, the confusion arises over Douglas's birth place. Douglas was born at Hopkins on March 9, 1919; he and his mother, Arvilla, were discharged from that facility on March 21 (Beck et al., 2009).

We do not know the building where Douglas spent his first 12 days, but it was not Harriet Lane. Harriet Lane was a pedi atric unit at Hopkins; babies were not de livered there. Douglas was born on another part of campus; he later moved to Harriet Lane.

In addition to pointing out that the Watson and Rayner (1920) quotation is consistent with information from Dou glas's first year, we think it is important to note that Powell's (2010) comment was based on a single source. Reliance on a single source can be problematic given the many ambiguities, inconsistencies, and contradictions in Watson's accounts of Al bert's conditioning. "One major source of confusion about the Albert story is Watson himself, who altered and deleted important aspects of the study in his major descrip tions of it" (Harris, 1979, p. 154).

To illustrate how dependence on a sin gle source can lead to misinterpretation of even seemingly straightforward statements, we briefly examine Watson's description of Albert in Behaviorism, a book that both Powell (2010) and Reese (2010) relied upon to support some of their comments. Watson (1924/1925) stated that Albert weighed "twenty-one pounds at eleven months of age. Albert was the son of one of the wet nurses in the Harriet Lane Hospital. He had lived his whole life in the hospital" (p. 125). This quote corroborates that $\mathrm{Al}$ bert's mother was a wet nurse and that the hospital he was referring to was Harriet Lane. However, in a typical inconsistency, Watson failed to confirm Albert's weight. In 1920, Albert reportedly weighed $21 \mathrm{lbs}$ at nine months (Watson \& Rayner, 1920). In 1924 (Watson, 1924/1925), Albert sup posedly weighed $21 \mathrm{lbs}$ at 11 months of age.

More important, the Behaviorism quote rewrites Albert's early history. No longer does Albert live "almost from birth" (Watson \& Rayner, 1920, p. 1) in a hospital environment, which is Powell's (2010) point, he now lives his "whole life in the hospital" (Watson, 1924/1925, p. 125). If a researcher were to rely exclusively on Watson's later quote as Powell did with Watson and Rayner, then he or she might erroneously conclude that Douglas could not be Albert because Douglas was brought to the hospital and Albert lived his entire first year there.

As the passage from Behaviorism shows, it is best to be wary of accepting the veracity of a single Watson statement or reading too much into a single Watson phrase. Seeking corroboration across mul tiple documents is important in dealing with most historical materials, but it is es sential when studying an author as incon sistent as Watson.

\section{The Adoption Myth}

Powell (2010) and Reese (2010) based the case for Albert's adoption on a single word from Watson (1924/1925). In Behaviorism, Watson (1924/1925) stated that Albert was "adopted by an out-of-town family" ( $p$. 132). The comments regarding Albert's purported adoption highlight the necessity for corroborative and converging evidence, without which the accuracy of a single phrase becomes questionable and its mean ing ambiguous. Our reply assumes that Powell and Reese meant a legal adoption; they may, however, have meant adoption in a more general sense. 
Powell (2010) objected to labeling Al bert's supposed adoption as a myth. He contended that we rejected "the adoption story on the basis of their discovery that Douglas left the hospital with his mother and remained with her until he died at age 6" (pp. 299-300). Actually, we felt that the adoption story warranted only a brief men tion because, although Watson's quote is not obscure, the vast majority of authors have ignored or disregarded as unproven the notion that Albert was adopted.

With respect to calling the story a myth, we did so because (a) after 90 years, no investigator has produced evidence collaborating a legal adoption, (b) there are ample reasons to be skeptical that a legal adoption occurred, (c) it is not clear if Watson was referring to a legal adoption, and (d) after expending considerable time and resources, I (H. P. Beck) was unable to uncover proof of a legal adoption.

Years before I heard of Douglas, I wondered why an adoption was not men tioned until four years after the study was performed and why Watson's other descriptions of the Albert investigation omit ted this information. Was the word "adopted" another imprecise use of terminology or one of Watson's inconsistencies?

I also questioned the likelihood that a poor child like Albert would be legally adopted. America in the 1920s was not the highly legally regulated society it is today. To adopt means "to take in." Poor children sometimes moved into the homes of persons with better resources than their par ents without involving the courts. That happened to Douglas's older brother Mau rice, who was raised by his grandparents. It is also very similar to what we later dis covered happened when the Brashears took Arvilla and Douglas in to become part of their family (Beck et al., 2009).

If we consider the possibility of a non legal adoption, nothing in Watson's state ment indicates that the Brashears were not the "out-of-town" family he was referring to. We cannot adequately assess that pos sibility because, if he knew, Watson re layed no additional information regarding Albert's post-Hopkins living arrangements. That is not surprising, as what mattered to Watson was that Albert was "out-of-town" and unavailable for further testing.

Despite my doubts, I did what I believe a number of others did before me. I verified that the 1920 adoption records were open to the public. Then I made many trips to Baltimore and the Maryland State Archives in Annapolis without finding proof of a legal adoption.

The research avenue that was open to me is open to any Watson scholar. For the adoption hypothesis to gain credibility, records must be produced of a boy match ing Albert's known characteristics. Until convincing documentation is found, the notion that Albert was legally adopted is most appropriately cataloged along with the many other unsubstantiated Watsonian myths.

\section{The Biometric Analyses}

Powell (2010) found the biometric analyses "highly inconclusive" (p. 299). We acknowledged that a confirmatory test, which would have allowed a positive identifica tion of Albert, could not be conducted because (a) Douglas's age at the time of the photograph is unknown and babies' facial features rapidly change, and (b) there were deficiencies in the resolution of Watson's (1923) movie.

A disconfirmatory test required less stringent criteria. That is, the photographic evidence might be sufficient to determine that Douglas was not Albert. Given that a disconfirmatory test was an option, we had an obligation to perform it. As we reported, resemblances were found between Albert's stills and Douglas's portrait. The biometric analyses indicated that Albert and Douglas could be the same person (Beck et al., 2009).

To dismiss all photographic evidence because the testing circumstances were not ideal would be to ignore results supporting the thesis that Douglas was Albert. If Douglas was not Albert, then it is likely that he would have failed the disconfirmatory test. Even a cursory visual inspection reveals that most infants do not look like Albert. Presumably, a biometric analysis would further reduce the number of infants passing a disconfirmatory test. Given the acknowledged limitations of the photo graphic evidence, the findings could not have provided more support for the hypothesis that Douglas was Little Albert.

\section{Was Publication of the Watson and Rayner Article Delayed?}

Reese (2010) objected to our conclusion that the evidence suggests that the February 1920 issue of the Journal of Experimental Psychology (JEP) was substantially de layed. This is an important question because the Albert study was published in the February issue, and we estimated that the last test session occurred in late March or early April. After deriving these dates, we searched for evidence that was consistent with these calculations but also evidence that was inconsistent with them.

To support his position, Reese (2010) proposed that $J E P$ did not lack for manu scripts and that Watson, as editor, had "plenty of time to allow publication of the February 1920 issue on time" (p. 300). We stated that Watson needed to solicit manuscripts, not that a dearth of submissions was the final hurdle he needed to overcome before resuming publication. The obstacles Watson faced in resurrecting the journal are unknown. We therefore refrained from making judgments regarding his use of time.

The February issue marked a resump tion of service, as publication had been suspended as Watson and other psycholo gists served in World War I. Our efforts to determine the time of publication included writing to the current editor of JEPGen eral, examining the February 1920 issue for signs of a telltale date, reviewing Watson's correspondence, and asking seri alists around the United States to check the receipt stamps on their JEP issues. We (a) uncovered a letter from Watson to Adolph Meyer suggesting that publication was de layed, (b) found no receipt stamp earlier than August 23, 1920, and (c) pointed out that a February publication date would have Watson making a movie before funds to purchase film had been authorized (Beck et al., 2009).

Reese (2010) labeled the receipt study "inconclusive" (p. 300) because "the date at Cornell was blurred and could have been August 23, 1920 or 1921, and the date at Harvard was for Issues 1 through 5" (p. 300). We assumed that the Cornell stamp was 1920 rather than 1921 , making it the earliest receipt record. That still allowed more than enough time for Watson and Rayner to finish the study in March or early April. We do not see why a single receipt date for the Harvard issues is troublesome. One stamp is exactly what we would ex pect if the five issues were mailed together, a finding that is consistent with a signifi cantly late publication.

In sum, although the exact publication date remains unknown, all available evi dence is consistent with the premise that the February 1920 issue was not released on time. Furthermore, the evidence we did uncover suggests that publication was sub stantially delayed. Thus, we did not revise our estimate that the final testing occurred in late March or early April.

\section{Was There a Second Film?}

Reese (2010) also objected to our estimate that baseline was filmed between Novem ber 28 and December 12, 1919. This criti cism assumes that Watson began "filming his work with infants earlier in 1919, with out the cited funding, and this filming could have included the pretest footage" 
(Reese, 2010, p. 300). What evidence is there, then, for a second film?

The archives at Hopkins contain many budgetary documents from Watson's ten ure as chairperson of the Psychology De partment. This correspondence includes letters between Watson and President Goodnow culminating in authorization to purchase film on November 19, 1919. No where is a second film mentioned. On No vember 13, Watson sent Goodnow still photographs showing some tests he hoped to film (Beck et al., 2009). Are we to be lieve that Watson had previously filmed babies but hid this information from Goodnow?

Confusion might understandably arise because of the titling of Watson's movie. The title screen of the film is Studies Upon the Behavior of the Human Infant. In 1923, the Stoelting Company began to distribute a 16-mm movie under the title The Experimental Investigation of Babies. Reese (2010) proposed that The Experimental In vestigation of Babies is lost. That is not correct. Allow us to relate a fascinating story.

As Reese accurately stated, all copies of the film were lost sometime after 1937. Watson scholars owe a great deal to Ben Harris. In 1979, he contacted the Stoelting Company (B. Harris, personal communica tion, September 24, 2008). Harris was told that several boxes of movies had been do nated to a "film unit" at the University of Michigan. There, under a stairwell, was Watson's film with the title screen Studies Upon the Behavior of the Human Infant. According to Harris, "The film was a dupe negative" from which he "arranged for a positive print to be made. The negative was stored off site, and eventually either the negative or another positive (the latter is more likely) was donated to Akron."

The connection between the Stoelting Company and the film under the stairwell seals the case. In 1923, Watson or someone at Stoelting decided to market the film un der the title, The Experimental Investiga tion of Babies. There is thus evidence of one, but not two, Watson baby movies.

The Other Half of the Story: Evidence That Douglas Merritte Was Little Albert

We believe that, within our allotted space, we have successfully addressed the major points that Powell (2010) and Reese (2010) felt were inconsistent with the proposition that Douglas was Little Albert. Scrutiny such as Powell and Reese provided is most appreciated. Nevertheless, attempts to find discrepancies with any hypothesis consider only half the story. Our closest approxima tion to the truth is gained, not by restricting ourselves to counterarguments, but also by considering the supportive evidence.

To demonstrate that Douglas was not Albert, it is necessary to attribute the many characteristics shared by the two boys to happenstance. No one has contended that Arvilla and Douglas were not at Hopkins when Watson and Rayner attempted to condition Albert. Neither has anyone con tested our position that there were never many, probably no more than four, in-res idence wet nurses at any one time (Beck et al., 2009). Douglas is one of very few chil dren who could have been Albert. The question reduces to this: Was Douglas $\mathrm{Al}$ bert's nursery mate or was he Albert?

In making that decision, consider the following: (a) Both Albert's and Douglas's mothers worked at the Harriet Lane Home. (b) Albert's mother was a wet nurse, and Arvilla gave birth on March 9, 1919, so she could have served as a wet nurse. (c) Doug las, like Albert, spent almost his entire first year at Harriet Lane. (d) Albert and Douglas left Hopkins during the early 1920s. (e) By jointly considering Watson and Rayner's (1920) article, the film, and Watson's correspondence with Goodnow, we determined that Albert was born be tween March 2 and March 16, 1919, a date that we believe is still firmly supported. Douglas was born on March 9, 1919. (f) Albert and Douglas were Caucasian males. (g) Visual inspection and biometric analy ses revealed facial similarities between $\mathrm{Al}$ bert and Douglas (Beck et al., 2009).

One may dismiss these commonalities as a rare series of coincidences. Or one may conclude that while each of these charac teristics applies to more than one person, the probability that the entire set applies to anyone other than Albert is exceptionally low. We believe that the available evidence strongly supports the proposition that Douglas Merritte was Little Albert.

\section{REFERENCES}

Beck, H. P., Levinson, S., \& Irons, G. (2009). Finding Little Albert: A journey to John B. Watson's infant laboratory. American Psychologist, 64, 605- 614. doi:10.1037/ a0017234

Harris, B. (1979). Whatever happened to little Albert? American Psychologist, 34, 151-160. doi:10.1037/0003-066X.34.2.151

Powell, R. A. (2010). Little Albert still missing. American Psychologist, 65, 299 -300. doi: $10.1037 / \mathrm{a} 0019288$

Reese, H. W. (2010). Regarding Little Albert. American Psychologist, 65, $300-301$. doi: 10.1037/a0019332

Watson, J. B. (Writer/Director). (1923). Experimental investigation of babies [motion picture]. (Distributed by C. H. Stoelting Co., 424 N. Homan Ave, Chicago, IL).

Watson, J. B. (1925). Behaviorism. New York, NY: Norton. (Original work published 1924) Watson, J. B., \& Rayner, R. (1920). Conditioned emotional reactions. Journal of Experimental Psychology, 3, 1-14. doi:10.1037/h0069608 